\title{
Adaptation of Staphylococcus aureus in a Medium Mimicking a Diabetic Foot Environment
}

\author{
Cassandra Pouget ${ }^{1}$, Claude-Alexandre Gustave ${ }^{2}\left(\mathbb{D}\right.$, Christelle Ngba-Essebe $^{1}$, Frédéric Laurent ${ }^{2,3}$, \\ Emmanuel Lemichez ${ }^{4}$, Anne Tristan ${ }^{2,3}$, Albert Sotto ${ }^{5}$, Catherine Dunyach-Rémy ${ }^{6}$ (1) \\ and Jean-Philippe Lavigne ${ }^{6, *} *(\mathbb{D})$
}

check for updates

Citation: Pouget, C.; Gustave, C.-A.; Ngba-Essebe, C.; Laurent, F.; Lemichez, E.; Tristan, A.; Sotto, A.; Dunyach-Rémy, C.; Lavigne, J.-P. Adaptation of Staphylococcus aureus in a Medium Mimicking a Diabetic Foot Environment. Toxins 2021, 13, 230. https:/ /doi.org/10.3390/toxins13030230

Received: 8 February 2021

Accepted: 18 March 2021

Published: 22 March 2021

Publisher's Note: MDPI stays neutral with regard to jurisdictional claims in published maps and institutional affiliations.

Copyright: (c) 2021 by the authors. Licensee MDPI, Basel, Switzerland. This article is an open access article distributed under the terms and conditions of the Creative Commons Attribution (CC BY) license (https:/ / creativecommons.org/licenses/by/ $4.0 /)$.
1 Virulence Bactérienne et Infections Chroniques, INSERM U1047, Université de Montpellier, 30908 Nîmes, France; cassandra.pouget@gmail.com (C.P.); ngbachristelle@yahoo.fr (C.N.-E.)

2 Centre International de Recherche en Infectiologie, Inserm U1111, CNRS UMR5308, ENS Lyon, Université Claude Bernard Lyon 1, 69365 Lyon, France; claude-alexandre.gustave@outlook.fr (C.-A.G.); frederic.laurent@univ-lyon.fr (F.L.); anne.tristan@chu-lyon.fr (A.T.)

3 Laboratoire de Bactériologie, Institut des Agents Infectieux, Centre National de Référence des Staphylocoques, Hôpital de la Croix-Rousse, Hospices Civils de Lyon, 69365 Lyon, France

4 Unité des Toxines Bactériennes, UMR CNRS 2001, Institut Pasteur, 75015 Paris, France; emmanuel.lemichez@pasteur.fr

5 Virulence Bactérienne et Infections Chroniques, INSERM U1047, Université de Montpellier, Department of Infectious and Tropical Diseases, CHU Nîmes, Univ Montpellier, 30908 Nîmes, France; albert.sotto@chu-nimes.fr

6 Virulence Bactérienne et Infections Chroniques, INSERM U1047, Université de Montpellier, Department of Microbiology and Hospital Hygiene, CHU Nîmes, Univ Montpellier, 30908 Nîmes, France; catherine.remy@chu-nimes.fr

* Correspondence: jean.philippe.lavigne@chu-nimes.fr; Tel.: +33-466-68-32-02; Fax: +33-466-68-42-54

\begin{abstract}
Staphylococcus aureus is the most prevalent pathogen isolated from diabetic foot infections (DFIs). The purpose of this study was to evaluate its behavior in an in vitro model mimicking the conditions encountered in DFI. Four clinical S. aureus strains were cultivated for 16 weeks in a specific environment based on the wound-like medium biofilm model. The adaptation of isolates was evaluated as follows: by Caenorhabditis elegans model (to evaluate virulence); by quantitative Reverse Transcription-Polymerase Chain Reaction (qRT-PCR) (to evaluate expression of the main virulence genes); and by Biofilm Ring test ${ }^{\circledR}$ (to assess the biofilm formation). After 16 weeks, the four S. aureus had adapted their metabolism, with the development of small colony variants and the loss of $\beta$-hemolysin expression. The in vivo nematode model suggested a decrease of virulence, confirmed by qRT-PCRs, showing a significant decrease of expression of the main staphylococcal virulence genes tested, notably the toxin-encoding genes. An increased expression of genes involved in adhesion and biofilm was noted. Our data based on an in vitro model confirm the impact of environment on the adaptation switch of $S$. aureus to prolonged stress environmental conditions. These results contribute to explore and characterize the virulence of $S$. aureus in chronic wounds.
\end{abstract}

Keywords: adaptation; biofilm; diabetic foot infection; EDIN; in vitro model; nematode; PantonValentin leukocidin; Staphylococcus aureus; virulence

Key Contribution: This paper highlights the impact of environmental conditions on Staphylococcus aureus in an in vitro model mimicking the conditions encountered in diabetic foot infections, a genomic and transcriptomic adaptation of $S$. aureus that could drive the escape to the host immune response and foster chronicity of the wound.

\section{Introduction}

Diabetes mellitus is a public health problem representing a major cause of mortality and morbidity worldwide [1]. This disease affects 442 million adults in the world 
and represents the seventh leading cause of death (Global report on diabetes: Executive Summary. Available online: https://www.who.int/health-topics/diabetes/publications\& publication=who-nmh-nvi-16.3 (accessed on 14 March 2021)). One of the most serious complications of diabetes mellitus is foot ulceration due to the triopathy associating ischemia, neuropathy, and arteriopathy [2-4]. It is a source of major suffering and financial costs for the patient, but also for the health care professionals and facilities and society. Infection in diabetic foot ulcer (DFU) is particularly frequent and, untreated, ultimately results in lowerlimb amputation [5]. Diabetic foot infection (DFI) is estimated to be the most common cause of diabetes-related admission in hospitals. Outcomes in patients presenting with a DFI are poor with a high mortality following this complication (around $15 \%$ in the following year) $[1,5]$. DFIs are polymicrobial and Staphylococcus aureus is the most frequent pathogen isolated [6,7]. This Gram-positive coccus is a leading cause of a wide range of diseases, from skin and soft tissue infections (SSTIs) (e.g., impetigo, carbuncles) to life-threatening bacteremia, toxic shock syndrome, endocarditis, and osteomyelitis $[6,8]$. However, the mechanisms of $S$. aureus pathogenicity and switch from colonization to infection in DFI remain unclear.

S. aureus deploys an arsenal of virulence factors to colonize, invade, and destroy tissues and host immune cells [9,10]. These virulence factors include adhesins (called microbial surface components recognizing adhesive matrix molecules (MSCRAMMs), such as fibronectin binding proteins (FnBPs), that bind to different host proteins and are important for tissular colonization [11,12]. The protein A (SpA) promotes immune evasion and protects against host-mediated clearance [10]. S. aureus also secretes toxins (e.g., the pore-forming cytotoxin alpha-hemolysin (Hla), which can lead to tissue necrosis. In addition, the superantigens can induce an unregulated polyclonal activation of lymphocyte $\mathrm{T}$ cells, leading to a cytokine storm. The regulation of these virulence factors is complex and extensive, but virulence is very closely regulated in S. aureus, notably owing to the agr gene. This bacterium can also secrete specific toxins such as the Panton-Valentine Leukocidin (PVL), which is a pore-forming toxin [6,13], or the exoenzymes EDINs (EDIN-A, -B, and -C), which inactivate the small GTPase RhoA to promote bacterial dissemination [14,15]. These cytolytic toxins can damage membranes of host cells, leading to cell lysis [16]. Finally, to adapt to the environmental conditions, S. aureus is able to survive in a metabolically inactive state while preserving the integrity of the host cell by forming small-colony variants (SCVs). SCVs differ metabolically and phenotypically to ordinary S. aureus isolates [17].

During DFI, S. aureus has been shown to activate its virulence factors to invade the tissue [18]. However, this infection is chronic and complex, with a different clinical presentation to SSTIs, notably with the mitigated impact of toxinogenic strains [6]. Indeed, S. aureus is exposed to various stress conditions in DFU: elevated glucose concentration, decreased temperature, decreased tissue oxygenation, and presence of antibiotics for several weeks [19]. Previous studies have analyzed the impact of antibiotics or glucose on the virulence of $S$. aureus strains during short-term [20-24] or long-term exposure [25-27] in a stress environment. These lifestyles involve forming quasi-dormant sub-populations and the presence of persister cells and SCVs [28]. Under prolonged nutrient limitation, the downregulation or loss of $a g r$ has been reported and seems to play a crucial role [17,28].

The purpose of this study was to evaluate the impact of an in vitro model mimicking the conditions encountered in DFU on the adaptation/switch in the virulence profile of $S$. aureus. This manuscript used the Lubbock wound pathogenic biofilm model [29] firstly adapted by De Leon et al. [30]. This model contains physiological concentrations of blood components, notably utilizing a chopped-meat-based medium supplemented with heparinized plasma and red blood cells. This medium was formulated to represent the conditions of human wounds and better simulate the nutrient environment in the chronic ulcer. In this study, the media formulation was modified by the addition of $10 \%$ glucose (allowing a concentration above $150 \mathrm{mg} / \mathrm{dL}$, the limit that defined an uncontrolled diabetes) and two antibiotics at sub-inhibitory concentrations (a condition frequently observed in this pathology due to arteriopathy). The antibiotics used correspond to two 
of the main molecules used in DFI: vancomycin, a glycopeptide that inhibits cell wall synthesis by binding to the D-Ala-D-Ala terminal of the growing peptide chain during cell wall synthesis; and linezolid, an oxazolidinone that disrupts bacterial growth by inhibiting the initiation process of protein synthesis by binding to a site on the bacterial $23 \mathrm{~S}$ ribosomal RNA of the $50 S$ subunit. Thus, $S$. aureus virulence was evaluated in this in vitro wound-like medium (WLM) that mimics a diabetic environment.

\section{Results}

\subsection{Phenotypic Effects on S. aureus after a Prolonged Culture in a Medium Mimicking a} DFU Environment

Firstly, we investigated the impact of the WLM supplemented with $10 \%$ glucose and/or vancomycin and linezolid tested at $0.5 \times$ minimum inhibitory concentration (MIC) on three virulent $S$. aureus strains (NSA739, NSA1077, and NSA7475) isolated from DFI and one colonizing strain (NSA1385) (Table 1). First, the presence/absence of $\beta$-hemolysis on blood agar plates and the emergence of SCVs were determined.

Table 1. S. aureus strains used in the study.

\begin{tabular}{ccc}
\hline Strains & Characteristics & References \\
\hline \multirow{2}{*}{ NSA739 } & S. aureus strain isolated from DFI (Grade 3), \\
PVL-, edin-, agr2, ST8 & {$[31]$} \\
NSA1385 & S. aureus strain isolated from colonized DFU (Grade 1), \\
PVL-, edin-, agr1, ST8 & {$[31]$} \\
NSA1077 & S. aureus strain isolated from DFI (Grade 3), \\
PVL+, edinB+, agr1, ST152 & \\
NSA7475 & S. aureus strain isolated from DFI (Grade 3), \\
& PVL-, edinB+, agr1, ST25 & [32] \\
\hline DFI, diabetic foot infection; DFU, diabetic foot ulcer; PVL, Panton-Valentine Leukocidin; ST, sequence type.
\end{tabular}

\subsubsection{Addition of $10 \%$ Glucose}

The WLM had no impact on the phenotype of the $S$. aureus strains tested after $24 \mathrm{~h}$ incubation, with or without the addition of glucose (Supplementary Materials Table S1). However, after 16 weeks in WLM alone, all the bacteria displayed mostly $\beta$-hemolytic activity (98-99\%), with low level SCV (1-2\%) (Table 2). The addition of 10\% glucose significantly modified the phenotype of the virulent strains with a clear loss of $\beta$-hemolytic production (particularly for NSA739 and NSA1077) and a high level of SCVs compared with the medium without glucose $(p<0.01)$. Interestingly, the colonizing NSA1385 was not significantly affected under any of the conditions tested (Table 2).

Table 2. Phenotypical modifications of $S$. aureus cultivated in an in vitro wound-like medium (WLM) mimicking the conditions encountered in chronic wounds and with the addition of other stress parameters (high glucose concentration, addition of antibiotics) for 16 weeks. Bold results are statistically significant $(p<0.01)$ compared with WLM alone.

\begin{tabular}{|c|c|c|c|c|c|c|c|c|c|c|c|c|}
\hline \multirow[t]{2}{*}{ Strains } & \multicolumn{2}{|c|}{ In Vitro WLM Alone } & \multicolumn{2}{|c|}{$\begin{array}{c}\text { WLM + } \\
10 \% \text { Glucose }\end{array}$} & \multicolumn{2}{|c|}{$\begin{array}{c}\text { WLM + } \\
\text { Vancomycin }\end{array}$} & \multicolumn{2}{|c|}{$\begin{array}{c}\text { WLM + } \\
\text { Linezolid }\end{array}$} & \multicolumn{2}{|c|}{$\begin{array}{c}\text { WLM + } \\
\text { 10\% Glucose + } \\
\text { Vancomycin }\end{array}$} & \multicolumn{2}{|c|}{$\begin{array}{c}\text { WLM + } \\
\text { 10\% Glucose + } \\
\text { Linezolid }\end{array}$} \\
\hline & $\beta$-hemol ${ }^{1}$ & $\mathrm{SCV}^{2}$ & $\beta$-hemol & SCV & $\beta$-hemol & SCV & $\beta$-hemol & SCV & $\beta$-hemol & SCV & $\beta$-hemol & SCV \\
\hline NSA739 & $99 \% \pm 2$ & $2 \% \pm 2$ & $12 \% \pm 5$ & $22 \% \pm 2$ & $93 \% \pm 5$ & $2 \% \pm 2$ & $28 \% \pm 4$ & $5 \% \pm 2$ & $5 \% \pm 2$ & $30 \% \pm 7$ & $13 \% \pm 6$ & $18 \% \pm 7$ \\
\hline NSA1077 & $98 \% \pm 3$ & $2 \% \pm 2$ & $5 \% \pm 5$ & $11 \% \pm 2$ & $91 \% \pm 7$ & $2 \% \pm 3$ & $55 \% \pm 5$ & $20 \% \pm 5$ & $8 \% \pm 4$ & $18 \% \pm 5$ & $10 \% \pm 10$ & $10 \% \pm 5$ \\
\hline NSA7475 & $98 \% \pm 2$ & $1 \% \pm 2$ & $65 \% \pm 3$ & $24 \% \pm 2$ & $88 \% \pm 7$ & $4 \% \pm 2$ & $48 \% \pm 2$ & $15 \% \pm 4$ & $50 \% \pm 5$ & $15 \% \pm 3$ & $37 \% \pm 8$ & $17 \% \pm 8$ \\
\hline NSA1385 & $99 \% \pm 2$ & $0 \% \pm 2$ & $93 \% \pm 7$ & $4 \% \pm 2$ & $100 \% \pm 2$ & $0 \% \pm 2$ & $75 \% \pm 5$ & $7 \% \pm 2$ & $94 \% \pm 2$ & $2 \% \pm 2$ & $91 \% \pm 5$ & $3 \% \pm 3$ \\
\hline
\end{tabular}

${ }^{1} \beta$-hemolysis. ${ }^{2}$ SCV, small colony variant. \% corresponds to a mean of counts ( \pm standard deviation) performed on three independent experiments on an average of 200 colonies.

\subsubsection{Addition of Antibiotics}

The addition of sub-MICs of vancomycin $(0.5 \times \mathrm{MIC})$ and linezolid $(0.5 \times \mathrm{MIC})$ in WLM supplemented with $10 \%$ glucose produced the same observations with a significant modification of the phenotype of the virulent strains (Table 2): a loss of $\beta$-hemolytic 
production (50-95\%) and a high level of SCVs (10-30\%) compared with WLM alone $(p<0.01)$. These modifications did not affect the colonizing strain NSA1385.

To clearly evaluate the effect of antibiotics, vancomycin and linezolid were tested alone in WLM. Interestingly, in sub-MIC of vancomycin alone, the modifications of S. aureus phenotype were variable, with a significant effect only on the $\beta$-hemolytic activity on NSA1077 and NSA7475 $(p<0.01)$. No statistical effect was noted for the level of SCV. The addition of linezolid alone significantly altered the $\beta$-hemolytic activity of all four tested strains $(p<0.01)$.

\subsection{Effect of a Prolonged Culture in a Medium Mimicking DFU Environment on S. aureus Virulence 2.2.1. Addition of $10 \%$ Glucose}

In the C. elegans model, all S. aureus strains killed the nematodes more rapidly than the avirulent $E$. coli OP50 strain used as nutrient for the nematodes $(p<0.001)$ (Table 3). The LT50 was similar for the three virulent strains (NSA739, NSA1077, and NSA7475), but significantly shorter $(p<0.001)$ for the colonizing strain (NSA1385) (1.7 to 2.3 days \pm 0.3 vs. $4.3 \pm 0.3$, respectively; Table 3 ). The differences in virulence were not due to differences in the survival and proliferation of strains within the nematode intestine, as the intestine colonization by the strains was not significantly different (Supplementary Materials Table S2).

Table 3. 50\% lethal time (in days) of Caenorhabditis elegans infected by different S. aureus cultivated in an in vitro wound-like medium (WLM) mimicking the conditions encountered in chronic wounds and with the addition of stress factors (high glucose concentration, sub-minimum inhibitory concentration (MIC) of antibiotics). The results are representative of at least four independent trials for each strain.

\begin{tabular}{|c|c|c|c|c|c|c|c|c|}
\hline Strains & $\begin{array}{l}\text { Length of } \\
\text { Preculture }\end{array}$ & $\begin{array}{l}\text { Without } \\
\text { Pre-Culture } \\
\text { in WLM }\end{array}$ & $\begin{array}{l}\text { WLM } \\
\text { Alone }\end{array}$ & $\begin{array}{c}\text { WLM + 10\% } \\
\text { Glucose }\end{array}$ & $\begin{array}{c}\text { WLM + } \\
\text { Vancomycin }\end{array}$ & $\begin{array}{c}\text { WLM + } \\
\text { Linezolid }\end{array}$ & $\begin{array}{c}\text { WLM + } \\
\text { 10\% Glucose + } \\
\text { Vancomycin }\end{array}$ & $\begin{array}{c}\text { WLM + } \\
\text { 10\% Glucose } \\
+ \text { Linezolid }\end{array}$ \\
\hline NSA739 $24 \mathrm{~h}$ & $24 \mathrm{~h}$ & $1.7 \pm 0.3$ & $3.5 \pm 0.2$ & $3.5 \pm 0.3$ & $3.4 \pm 0.2$ & $3.8 \pm 0.3$ & $3.9 \pm 0.2$ & $5.00 \pm 0.4$ \\
\hline NSA739 16-week & 16 weeks & NA & $3.9 \pm 0.2$ & $4.9 \pm 0.2$ & $3.2 \pm 0.3$ & $4.9 \pm 0.2$ & $5.0 \pm 0.2$ & $4.9 \pm 0.2$ \\
\hline NSA1077 $24 \mathrm{~h}$ & $24 \mathrm{~h}$ & $2.2 \pm 0.2$ & $3.9 \pm 0.2$ & $4.2 \pm 0.3$ & $4.1 \pm 0.1$ & $4.3 \pm 0.2$ & $4.4 \pm 0.1$ & $4.9 \pm 0.2$ \\
\hline NSA1077 16-week & 16 weeks & NA & $4.4 \pm 0.1$ & $5.4 \pm 0.4$ & $3.7 \pm 0.2$ & $5.4 \pm 0.4$ & $5.5 \pm 0.3$ & $5.5 \pm 0.4$ \\
\hline NSA7475 $24 \mathrm{~h}$ & $24 \mathrm{~h}$ & $2.3 \pm 0.3$ & $3.8 \pm 0.2$ & $3.9 \pm 0.3$ & $3.7 \pm 0.2$ & $3.5 \pm 0.2$ & $3.8 \pm 0.2$ & $5.2 \pm 0.4$ \\
\hline NSA7475 16-week & 16 weeks & NA & $4.3 \pm 0.3$ & $5.3 \pm 0.4$ & $3.5 \pm 0.2$ & $4.7 \pm 0.3$ & $5.4 \pm 0.4$ & $5.0 \pm 0.2$ \\
\hline $138524 \mathrm{~h}$ & $24 \mathrm{~h}$ & $4.3 \pm 0.3$ & $4.8 \pm 0.3$ & $4.6 \pm 0.3$ & $4.3 \pm 0.4$ & $5.1 \pm 0.2$ & $4.8 \pm 0.3$ & $4.4 \pm 0.2$ \\
\hline 1385 16-week & 16 weeks & NA & $5.0 \pm 0.4$ & $5.2 \pm 0.2$ & $5.1 \pm 0.2$ & $5.1 \pm 0.3$ & $4.9 \pm 0.3$ & $4.9 \pm 0.2$ \\
\hline $\begin{array}{c}\text { OP50 (Control } \\
\text { strain) }\end{array}$ & - & $7.7 \pm 0.2$ & NA & NA & NA & NA & NA & NA \\
\hline
\end{tabular}

In bold, $p<0.01$ after a pairwise comparison between LT50s (strain in WLM alone vs. others) using a log rank test. NA, not applicable.

Infecting S. aureus strains pre-cultivated for $24 \mathrm{~h}$ in WLM showed significantly decreased virulence compared with the same strains without pre-culture (1.7-2.3 days \pm 0.3 vs. 3.5-3.9 \pm 0.2 , respectively; $p<0.001$, Table 3 ). No impact was noted on virulence when these strains were pre-cultivated for 16 weeks (3.5-3.9 \pm 0.2 vs. 3.9-4.4 \pm 0.2 , respectively; $p=$ not significant (NS), Table 3). Interestingly, no significant difference of LT50 was noted for the colonizing strain, irrespective of the length of pre-culture ( $24 \mathrm{~h}$ vs. 16 weeks), although an increased nematode lifespan was noted: 4.3 days \pm 0.3 , without pre-culture; $4.8 \pm 0.3$, with a $24 \mathrm{~h}$ pre-culture; and $5.0 \pm 0.4$, with a 16 -week pre-culture $(p=\mathrm{NS})$ (Table 3).

When the infecting S. aureus strains were pre-cultivated in WLM supplemented with $10 \%$ glucose, their virulence was similar to that observed after pre-culture in WLM alone (3.5-3.9 \pm 0.2 vs. 3.5- $4.2 \pm 0.3$, respectively; $p=\mathrm{NS}$, Table 3$)$. In contrast, the virulence of the three infecting strains was significantly decreased after a 16-week pre-culture in the glucose supplemented medium compared with medium alone (4.9-5.4 \pm 0.4 vs. $3.9-4.4 \pm 0.3$, respectively; $p<0.001$, Table 3).

As previously observed, no significant modification of lifespan of the C. elegans was observed in the colonizing strain NSA1385 after a short or a long pre-culture in the WLM 
with or without glucose ( 24 h: $4.8 \pm 0.3$ vs. $4.6 \pm 0.3$ and 16-week: $5.0 \pm 0.4$ vs. $5.2 \pm 0.2$, respectively; $p=$ NS, Table 3 ).

\subsubsection{Addition of Antibiotics}

The addition of vancomycin to the WLM had no effect on the lifespan of nematodes in the presence of S. aureus. No significant difference of LT50 of nematodes fed with the different strains was observed when these strains were pre-cultivated for $24 \mathrm{~h}$ or 16 weeks in medium plus antibiotic ( $p=$ NS) (Table 3). However, a trend for increased virulence could be noted for the three infecting $S$. aureus strains pre-cultivated with vancomycin versus without pre-culture (LT50: $3.2-3.7$ days \pm 0.4 vs. 3.9-4.4 \pm 0.3 , respectively; $p=$ NS, Table 3).

The addition of linezolid also had no significant impact on the virulence of the infecting S. aureus pre-cultivated in supplemented WLM for $24 \mathrm{~h}$ compared with a pre-culture in WLM medium alone (3.5-4.3 \pm 0.3 vs. 3.5-3.9 \pm 0.2 , respectively; $p=$ NS, Table 3 ). Interestingly, during a long period of pre-culture (16 weeks), a significant increase of the lifespan of the C. elegans was observed in two of the three virulent $S$. aureus strains (NSA739 and NSA1077) (4.9-5.4 \pm 0.4 vs. 3.9-4.4 \pm 0.2 , respectively; $p<0.001$, Table 3). No significant modification of lifespan of the $C$. elegans was observed in the colonizing strain NSA1385 after a short or long pre-culture in the WLM with or without addition of antibiotics ( 24 h: $4.8 \pm 0.3$ vs. $5.1 \pm 0.2$ and 16-week: $5.0 \pm 0.4$ vs. $5.1 \pm 0.3$, respectively; $p=$ NS, Table 3 ).

The addition of vancomycin to WLM supplemented with $10 \%$ glucose showed the same observation as pre-cultivation without antibiotic. A significant decrease of $S$. aureus virulence was shown for the isolates pre-incubated for 16 weeks $(5.0-5.5 \pm 0.4 \mathrm{vs}$. $3.9-4.4 \pm 0.3$, respectively; $p<0.001$, Table 3), suggesting a role of glucose alone in this effect.

While the same observation was noted for the long exposure of two of the three isolates (NSA739 and NSA1077) in WLM medium supplemented with $10 \%$ glucose and linezolid (4.9-5.5 \pm 0.4 vs. 3.9-4.4 \pm 0.2 , respectively; $p<0.001$, Table 3$)$, a clear impact of linezolid was also observed after a short exposure $(24 \mathrm{~h})$ of the three infecting $S$. aureus to this medium (4.9-5.2 \pm 0.4 vs. 3.5-3.9 \pm 0.2 , respectively; $p<0.001$, Table 3$)$, suggesting an effect of linezolid on $S$. aureus virulence in the WLM supplemented with glucose.

Finally, no impact of the addition of antibiotics and glucose to WLM medium was noted for the colonizing strain NSA1385 (Table 3).

\subsection{Effect of a Prolonged Culture in a Medium Mimicking DFU Environment on Kinetics of S. aureus Biofilm Formation}

The Biofilm Ring test ${ }^{\circledR}$ was performed to evaluate the effect of WLM with or without the addition of $10 \%$ glucose and antibiotics on the capacity of S. aureus to form biofilm.

\subsubsection{Addition of $10 \%$ Glucose}

The pre-cultivation of S. aureus in WLM supplemented with glucose had no significant effect on biofilm formation for all the studied strains after a short exposure (24 h) (Supplementary Materials Table S3).

After a long exposure (16 weeks) of the infecting strains with the WLM supplemented with $10 \%$ glucose, all the strains had impeded potential to form biofilm (Figure 1).

For NSA739 and NSA7475, biofilm was completely formed after $5 \mathrm{~h}$ of incubation $(\mathrm{BFI}=1.5 \pm 0.2)$. When the strain was pre-cultivated in WLM $+10 \%$ glucose, we observed a trend of faster formation of biofilm (at 2 and $3 \mathrm{~h}$ ), but no impact on the biofilm formation at the end-point $(5 \mathrm{~h})$.

For NSA1077, the strain pre-cultivated with glucose showed a significantly faster biofilm formation than the strain pre-cultivated in WLM alone at 2,3, and $4 \mathrm{~h}$, with the beads immobilized after $4 \mathrm{~h}(\mathrm{BFI}=1.6 \pm 0.2)(p<0.001)$.

For the colonizing strain NSA1385, the addition of glucose had no impact on the kinetics of biofilm formation: the BFI values were similar between all conditions tested. 


\subsubsection{Addition of Antibiotics}

As observed with glucose supplementation, pre-cultivation of S. aureus in WLM plus antibiotics (with or without 10\% glucose) had no effect on biofilm formation for all the studied strains after a short exposure (24 h) (Supplementary Materials Table S3).

For the three infecting strains NSA739, NSA1077, and NS7475, the kinetics of biofilm formation were slowed in the presence of sub-MIC of vancomycin alone, with a biofilm not constituted after $5 \mathrm{~h}(p<0.0001)$ (Figure 1). Interestingly, although the addition of sub-MICs of linezolid had no effect on the biofilm formation of NSA7475 or NSA1077, pre-cultivation of these strains in WLM plus antibiotics and 10\% glucose had a significant effect, with the beads immobilized at $3 \mathrm{~h}(p<0.001)$.

Antibiotic pressure had no significant impact on the kinetics of biofilm formation for the colonizing strain NSA1385 (Figure 1).

A

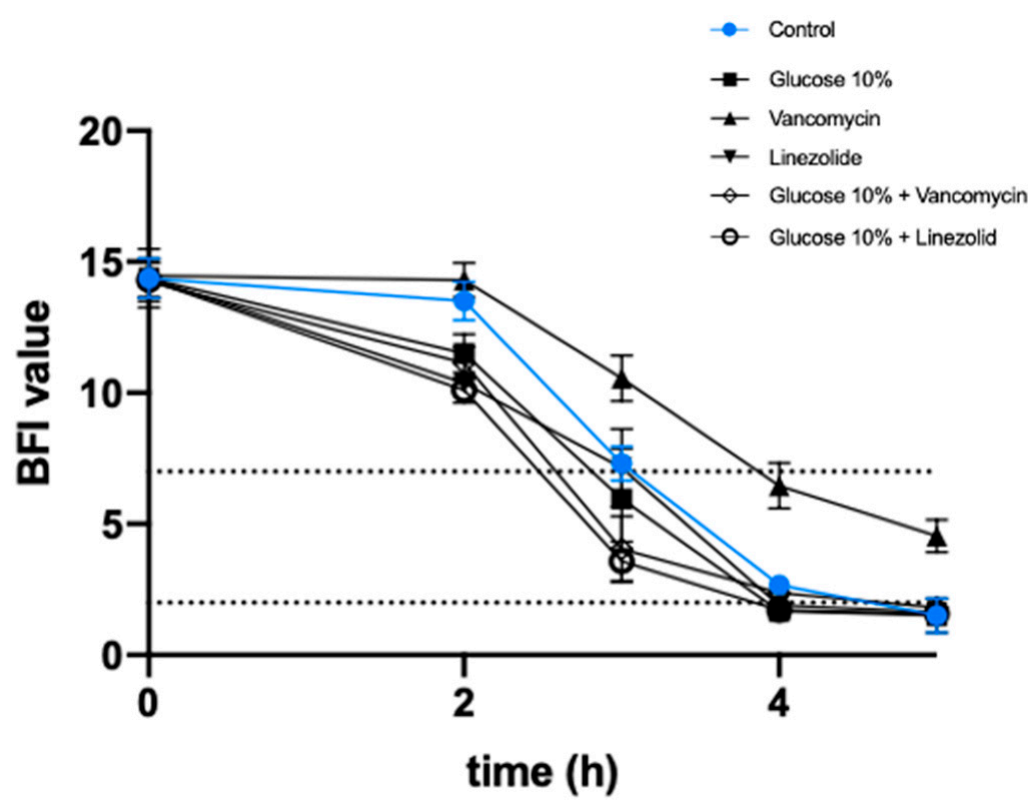

B

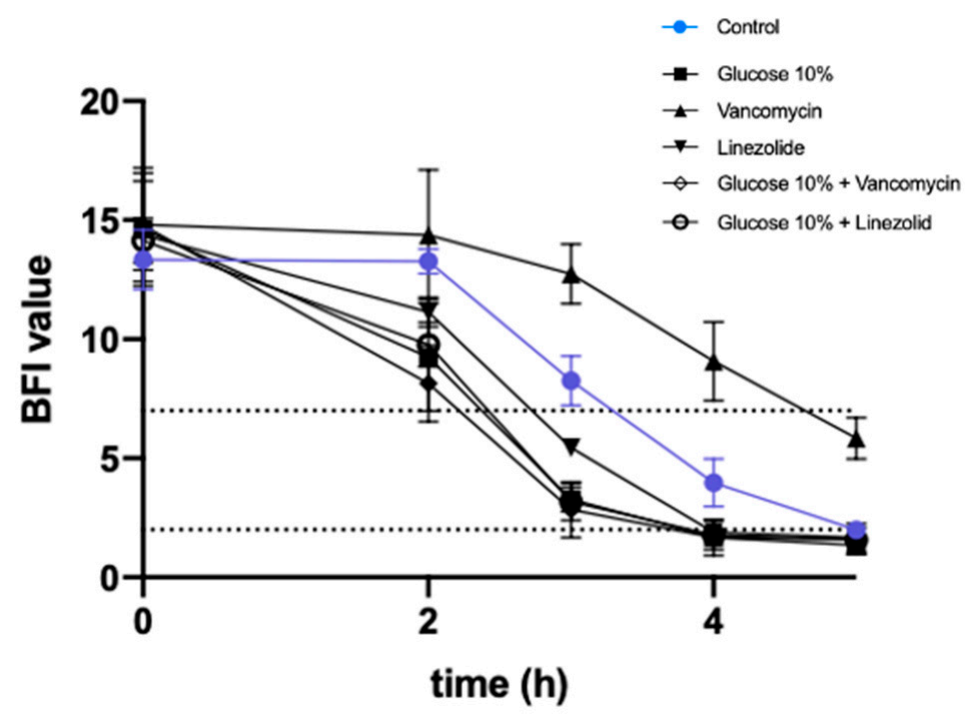

Figure 1. Cont. 
C

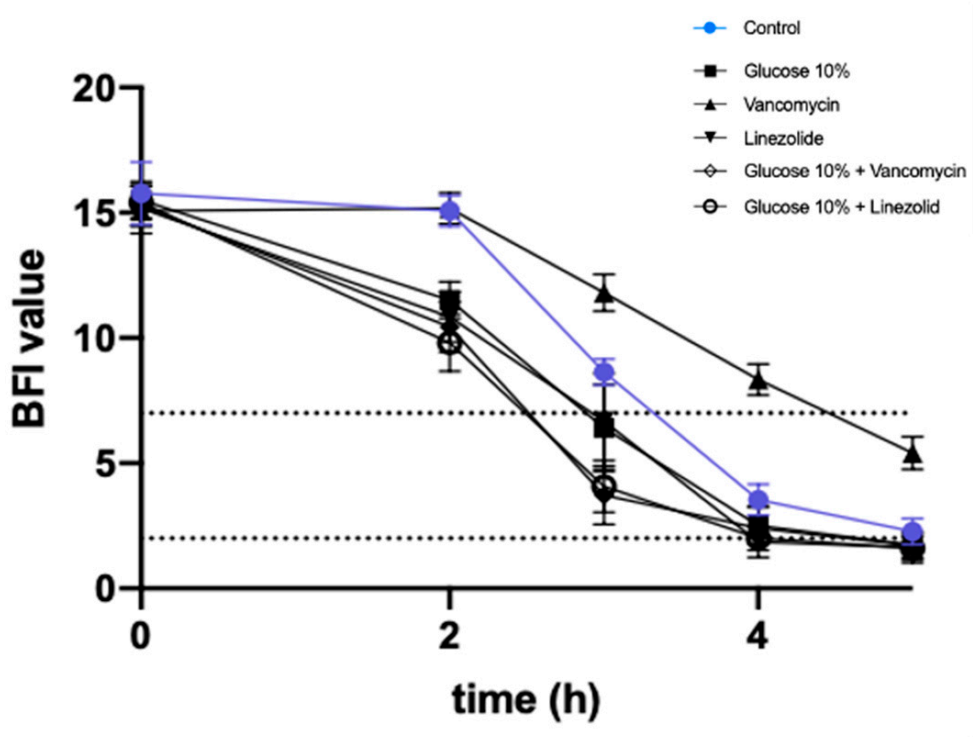

D

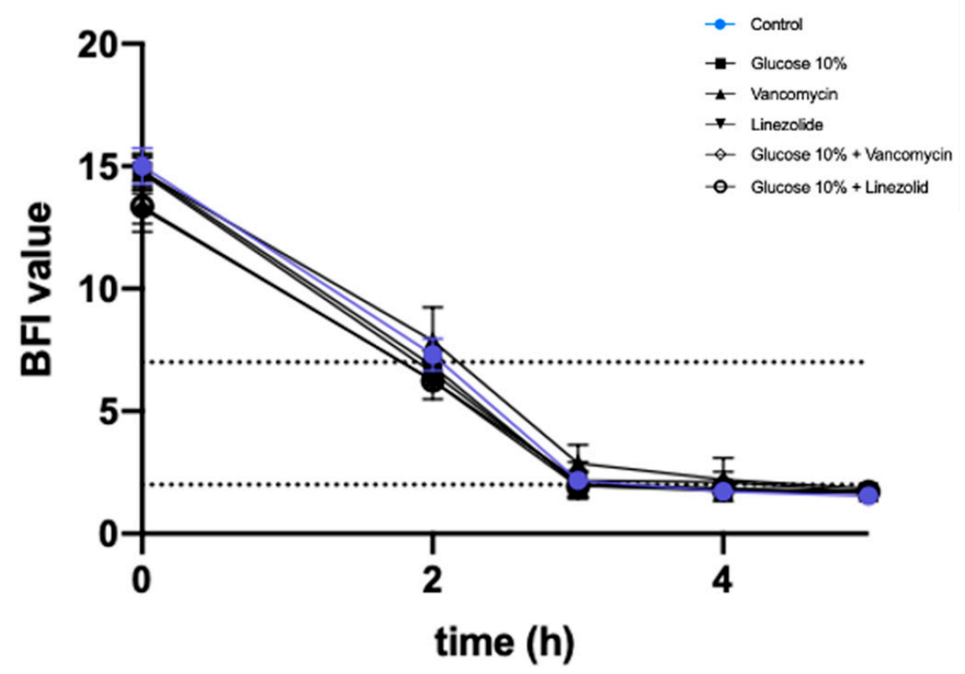

Figure 1. Effects of a pre-culture in a wound-like medium (WLM) and 10\% glucose combined with sub-minimum inhibitory concentration (MIC) of vancomycin $(0.5 \times$ MIC) and linezolid $(0.5 \times$ MIC) on S. aureus biofilm formation after 16 weeks of culture. The kinetics of the early phase of biofilm formation were determined on (A) NSA739; (B) NSA1077; (C) NSA7475; and (D) NSA1385 by the BioFilm ring test ${ }^{\circledR}$ (BioFilm Control, France). The control corresponds to the evaluation of biofilm formation of strains in Brain Heart Infusion (BHI) medium alone. Dotted horizontal lines: >7, no biofilm; $<2$, fixed biofilm. Means \pm standard errors of the mean of biofilm indexes (BFIs) for at least three independent replicates are presented. Statistical differences between the different culture conditions at each time were obtained using two-way analysis of variance (ANOVA), followed by Dunnett's multiple-comparison test.

\subsection{Effect of a Prolonged Culture in a Medium Mimicking DFU Environment on S. aureus Genes' Expression}

To assess the impact of WLM on bacteria at the genetic level, the expression levels of some important genes involved in $S$. aureus virulence were measured. Their log relative transcription levels are shown in Supplementary Materials Table S4 for all the strains and Figures 2 and 3 for NSA1077 and NSA739, respectively. 


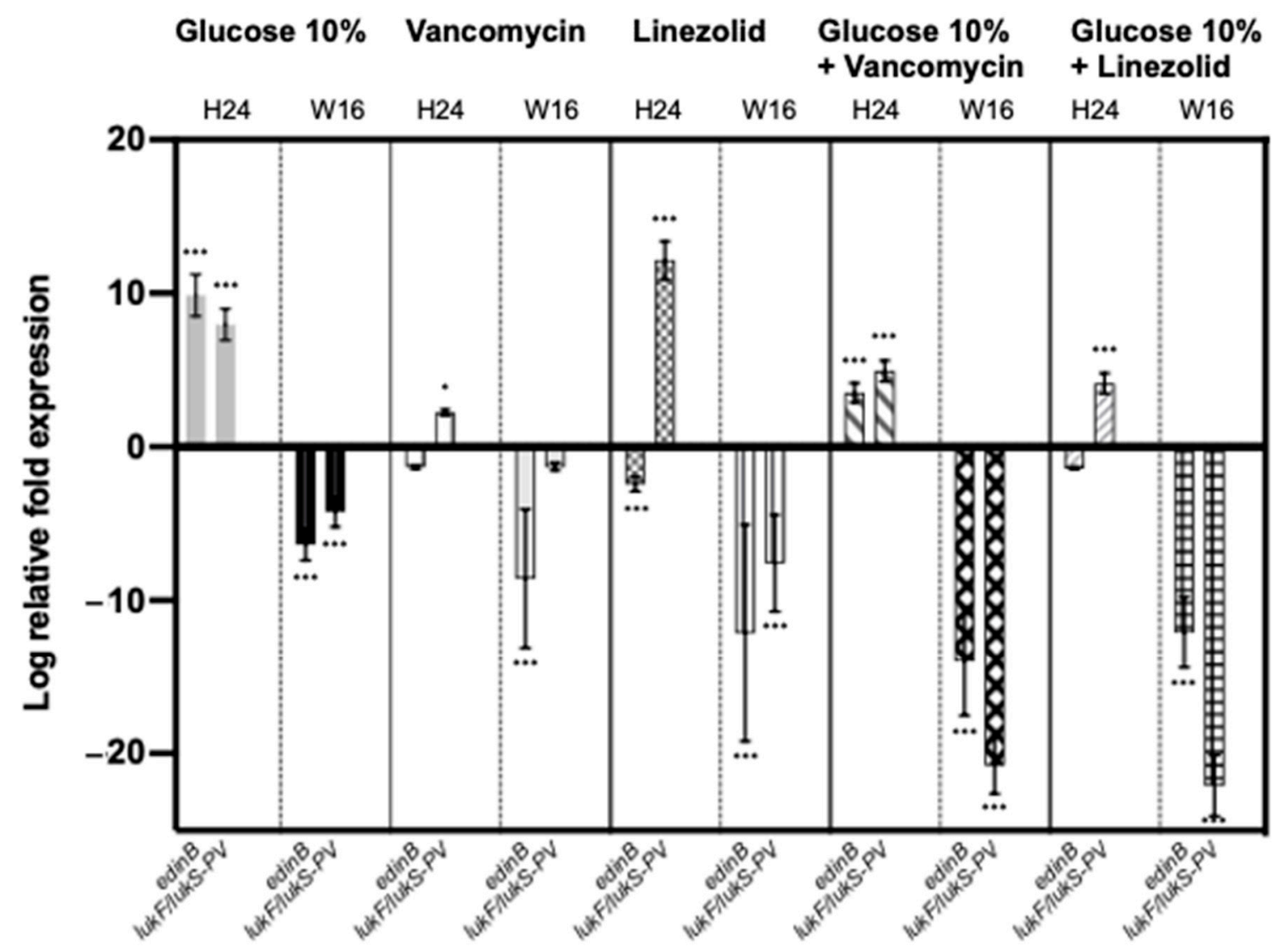

Figure 2. Relative mRNA expression levels of toxinogenic genes of $S$. aureus NSA1077 strain cultivated in WLM supplemented with $10 \%$ glucose, vancomycin $(0.5 \times \mathrm{MIC})$, linezolid $(0.5 \times \mathrm{MIC}), 10 \%$ glucose + vancomycin $(0.5 \times \mathrm{MIC})$, and $10 \%$ glucose + linezolid $(0.5 \times \mathrm{MIC})$ after $24 \mathrm{~h}(\mathrm{H} 24)$ and 16 weeks (W16). The log-transformed averages of relative fold changes of NSA1077 in different environmental media compared with NSA1077 in Luria-Bertani (LB) medium for $24 \mathrm{~h}$ and 16 weeks are presented. The error bars represent the standard deviations from the three independent RNA preparations. Significant differences from the NSA1077 in LB medium for $24 \mathrm{~h}$ and 16 weeks using Dunnett's test are indicated. ${ }^{*}, p<0.01$; $* * *, p<0.001$.

Globally, the expression of studied genes was not significantly affected in strains pre-cultivated in WLM alone (Supplementary Materials Table S4).

\subsubsection{Addition of $10 \%$ Glucose}

After $24 \mathrm{~h}$ of exposure to WLM and 10\% glucose, spa gene, which encodes protein A (a major colonizing factor), was significantly decreased in all the infecting S. aureus strains $(p<0.05$ to $p<0.001)$ (Supplementary Materials Table S4). Moreover, the two toxinogenic $p v l$ and $e$ din-B genes were significantly upregulated $(p<0.001)$ in the two strains harboring these genes: NSA1077 (Figure 2) and NSA7475 (Supplementary Materials Table S4).

No modification in the expression of any tested gene was noted in the colonizing strain NSA1385 (Supplementary Materials Table S4).

The same trend was observed after a long exposure of the infecting strains in WLM supplemented with $10 \%$ glucose: hla, which encodes the $\alpha$-hemolysin (another major virulence factor); sea, which encodes the staphylococcal enterotoxins (exotoxins with pyrogenicity, superantigenicity, and capacity to enhance lethality of endotoxin); and the global regulator of the staphylococcal virulence, agr genes, were significantly down-regulated $(p<0.001)$ (Supplementary Materials Table S4, Figure 3). Moreover, the expressions of the toxinogenic PVL- and EDIN-encoding genes were also significantly decreased $(p<0.001)$ (Supplementary Materials Table S4, Figure 2). In contrast, spa and fnbpA genes were signifi- 
cantly over-produced when S. aureus strains were pre-cultivated in WLM supplemented with $10 \%$ glucose $(p<0.001)$ (Supplementary Materials Table S4, Figure 3).

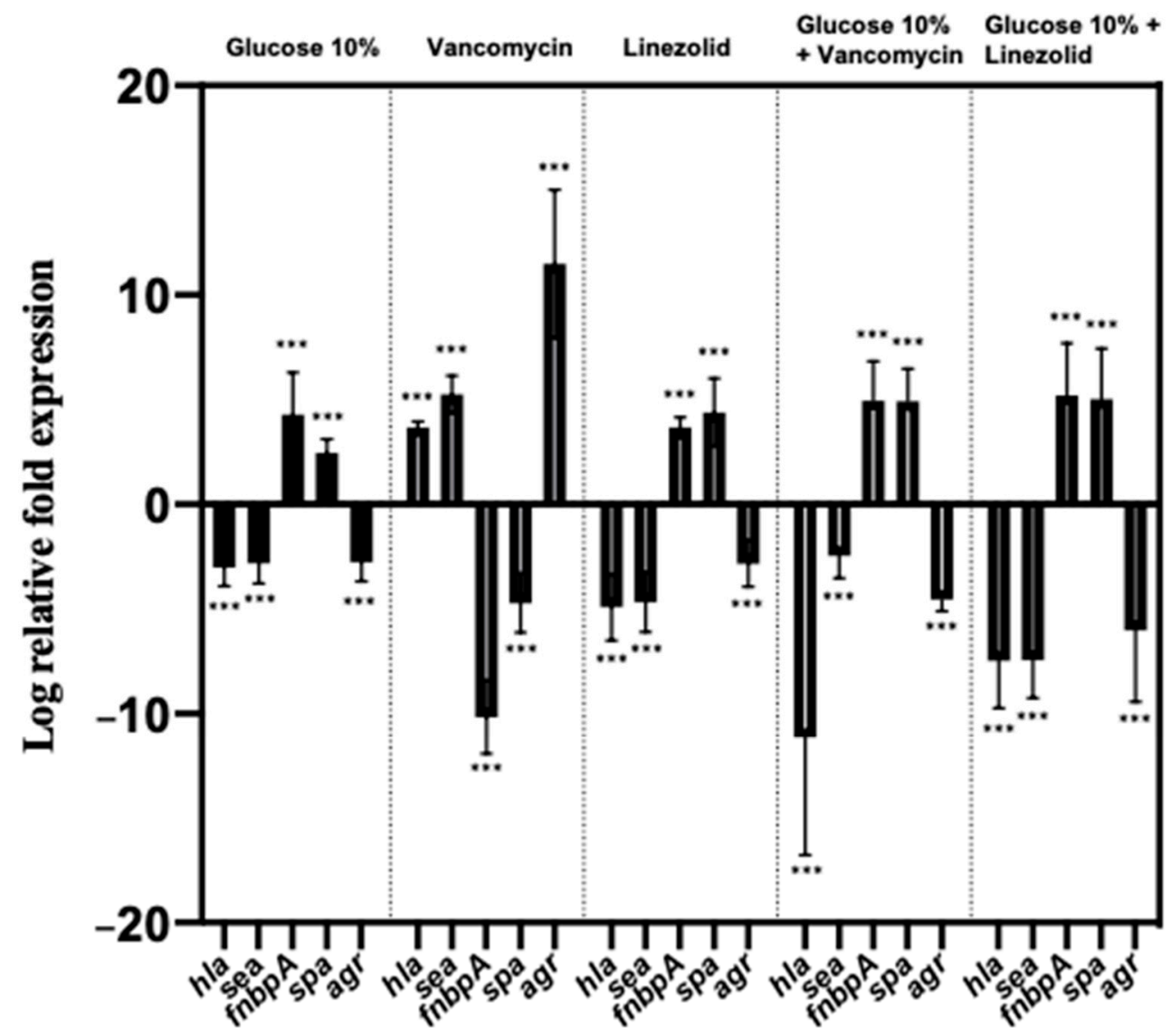

Figure 3. Relative mRNA expression levels of virulence genes and a regulator gene of $S$. aureus NSA739 strain cultivated in WLM supplemented with $10 \%$ glucose, vancomycin $(0.5 \times$ MIC), linezolid $(0.5 \times$ MIC), $10 \%$ glucose + vancomycin $(0.5 \times$ $\mathrm{MIC})$, and $10 \%$ glucose + linezolid $(0.5 \times \mathrm{MIC})$ after a long exposure (16 weeks). The log-transformed averages of relative fold changes of NSA739 in different environmental media compared with NSA739 in LB medium are presented. The error bars represent the standard deviations from the three independent RNA preparations. Significant differences from the NSA739 in LB medium using Dunnett's test are indicated. ${ }^{* * *}, p<0.001$.

The expression of the studied genes was not modified in any conditions of precultivation for the colonizing strain NSA1385 (Supplementary Materials Table S4).

\subsubsection{Addition of Antibiotics}

With sub-MIC of vancomycin: Short pre-cultivation of the infecting S. aureus strains in WLM plus vancomycin $(24 \mathrm{~h})$ did not significantly modify the expression of the virulence genes tested (Supplementary Materials Table S4).

After a long exposure of the infecting strains with the WLM + sub-MIC of vancomycin, $h l a$, sea, and agr genes were significantly up-regulated $(p<0.001)$. In contrast, the expression of $f n b p A$ and spa genes was significantly decreased $(p<0.001)$ (Supplementary Materials Table S4, Figure 3). Interestingly, although pol gene was not affected by this pre-cultivation, the toxinogenic edinB gene was significantly under-expressed $(p<0.001)$ (Supplementary Materials Table S4, Figure 2).

No significant modification in the expression of any studied gene was observed for any pre-cultivating conditions of the colonizing strain NSA1385 (Supplementary Materials Table S4). 
With sub-MIC of vancomycin $+10 \%$ glucose: The infecting $S$. aureus strains precultivated for $24 \mathrm{~h}$ presented a significant increase of $f n b p A, s p a, p v l$, and edinB expression $(p<0.001)$ (Supplementary Materials Table S4). Moreover, a decrease of the expression of hla gene was noted for NSA1077 $(p<0.05)$.

Contrary to the results with WLM plus vancomycin alone, hla, sea, and agr genes were significantly down-regulated after a long exposure of the infecting strains in WLM + glucose + vancomycin $(p<0.001)$ (Supplementary Materials Table S4, Figure 3). Moreover, the expression of $f n b p A$ and spa genes was significantly increased $(p<0.001)$ (Supplementary Materials Table S4, Figure 3). Finally, the PVL- and EDIN-encoding genes were significantly under-expressed $(p<0.001)$ (Supplementary Materials Table S4, Figure 2).

After a long exposure of the colonizing strain NSA1385 to the medium, an increased expression of $f n b p A$ gene $(p<0.001)$ and a decrease of hla gene $(p<0.05)$ (Supplementary Materials Table S4) were observed.

With sub-MIC of linezolid: After a $24 \mathrm{~h}$ exposure of the infecting strains in the WLM + linezolid, hla, sea, and spa genes were significantly down-regulated (with the exception of spa gene in NSA739) $(p<0.05$ to $p<0.001)$. In contrast, the expression of fnbpA gene was notably increased in NSA739 $(p<0.001)$ (Supplementary Materials Table S2). Interestingly, while PVL-encoding genes were over-produced in this condition, the toxinogenic edinB genes were significantly under-expressed $(p<0.001)$ (Supplementary Materials Table S4).

After a 16-week exposure of the infecting strains to WLM + linezolid, hla, sea, and agr genes were significantly down-regulated $(p<0.001)$ (Supplementary Materials Table S4, Figure 3). In contrast, the expressions of $f n b p A$ and spa genes were significantly increased $(p<0.001)$ (Supplementary Materials Table S4, Figure 3). All the toxinogenic-encoding genes were significantly under-expressed $(p<0.001)$ (Supplementary Materials Table S4, Figure 2).

No significant modification of the expression of the studied genes was observed in any conditions of pre-cultivation for the colonizing strain NSA1385 (Supplementary Materials Table S4).

With sub-MIC of linezolid $+10 \%$ glucose: The addition of glucose replicated the results observed with linezolid alone. Two infecting S. aureus strains (NSA739 and NSA1077) pre-cultivated in this condition for 24 h presented a significant decrease of hla and sea genes' expression $(p<0.05)$, and the infecting strain NSA7475 showed a decrease of spa gene $(p<0.001)$ (Supplementary Materials Table S4). Moreover, an increase of the expression of fnbpA gene was noted for NSA739 $(p<0.001)$. The PVL-encoding gene was over-expressed in this condition $(p<0.001)$. The only difference concerned the toxinogenic edin $B$ gene, which was not significantly modified (Supplementary Materials Table S4).

These different observations were replicated after a long exposure, with a significant decrease of expression of $h l a$, sea, and agr genes $(p<0.001)$ and a significant over-expression of $f n b p A$ and spa genes $(p<0.001)$ (Supplementary Materials Table S4, Figure 3). The PVLand EDIN-encoding genes were significantly under-expressed in this condition $(p<0.001)$ (Supplementary Materials Table S4, Figure 2).

Finally, the colonizing strain NSA1385 was significantly affected after a long exposure, with a decrease of hla gene expression $(p<0.05)$ and an increase of $f n b p A$ gene expression $(p<0.001)$ (Supplementary Materials Table S4).

\section{Discussion}

The host-microbiota interface is often the key point in the development of wound infections. Various studies have described the DFU microbiota to determine the role of microorganisms [33]. Although they have produced interesting results and confirmed that the microbiota is a highly dynamic microbial community that maintains a relationship with the host, better understanding of the complex competitive or synergistic interaction between commensal and/or pathogenic microorganisms is necessary as it could affect the severity and progression of the wound [7]. The virulence capacity of a bacterium has a direct impact on the equilibrium between colonization and infection [34]. However, in 
chronic wounds, bacteria can adapt their virulence, such as forming a polymicrobial biofilm community [35]. These biofilms may be responsible for the delayed healing of these chronic wounds [36]. Bacterial interactions play an important role in pathogenesis, competing and cooperating in order to support their mutual growth in a specific environment [37]. However, it seems that the behavior of bacteria can also be greatly influenced by the environmental conditions [24]. Here, we evaluated the role of a high glucose concentration and sub-MICs of two antibiotics in a WLM mimicking the conditions encountered in DFU on a series of clinical bacterial strains isolated from this clinical situation. To study bacterial virulence, most studies have previously used in vitro planktonic cultures on rich media or in vivo diabetes animal models (e.g., $\mathrm{db} / \mathrm{db}$ mice), but without the ability to create genuine wound chronicity [7]. The WLM represents a convenient and reliable model to study bacteria in a relevant environment $[29,30]$.

Using the WLM, we observed that this environment clearly impacts bacterial behavior, and its virulence. Firstly, we observed that a long exposure of S. aureus in the medium significantly decreased the bacterial virulence in a C. elegans model (Table 3). Moreover, the addition of $10 \%$ glucose (a condition similar to that encountered in DFU) more drastically affected the behavior of the infecting bacteria (Table 4): the strains significantly decreased their virulence in the nematodes model (Table 3), in parallel with dramatic under-expression of the virulent genes (and decreased $\beta$-hemolytic activity) and an overexpression of genes involved in adhesion and colonization (Figure 3, Supplementary Materials Supplementary Materials Table S4), as observed by Kalan et al. [38]. The bacterial stress induced by the glucose accelerated biofilm formation (Figure 1) and significantly increased SCV phenotypes (Table 2). These observations support previous clinical studies demonstrating that biofilms were implicated in 60 to $80 \%$ of chronic wounds versus $6 \%$ for acute wounds $[39,40]$. Bacteria within biofilms evade the host's natural defenses and are resistant to the host immune defense. Stimulation of the immune system without effectively eradicating the infection causes collateral damage to surrounding tissue and causes chronic inflammation [41]. This persistent chronic inflammation, exacerbated by the diabetic immune context, leads to the production of auto-inflammatory cytokines that aggravate the wound and slow the healing process. The influence of glucose on bacterial virulence has been studied by Regassa et al. [42]. They noted that glucose inhibited the expression of agr gene in S. aureus. The effect on this regulator gene directly reduced the virulence expression, as observed in our study. Moreover, the influence of glucose on the poly- $N$-acetylglucosamine synthesis, the most common components of biofilm in $S$. aureus, has been previously described [43-45]. Glucose stimulates the gbaAB operon that regulates biofilm formation through activating the expression of the ica operon in S. aureus. GbaA is modulated by inducing compounds and facilitates S. aureus to adapt to stress via aggregation of biofilm formation [46], as we found here. Interestingly, the response of neutrophils towards $S$. aureus also varies depending on the available glucose. S. aureusmediated NET (neutrophil extracellular trap) release (a process used by neutrophils to kill or trap pathogens) is impaired at a high glucose concentration [47], notably due to an ejection of NET by vesicles outside neutrophils [48]. NET diffusion contributes to extensive tissue damage in the host and could participate in wound chronicity.

Antistaphylococcal regimens must be taken into account in the influence on bacterial virulence, as previously determined [24]. In our study, we observed that vancomycin and linezolid acted differentially on S. aureus virulence. This could be explained by the impact of these antibiotics on the expression of regulation of several virulence genes, possibly affecting the expression of the agr system. Previous in vitro studies have shown a decreased level of virulence expression upon treatment with ribosomally active antibiotics [24]. Here, the same trend was noted when the bacteria were pre-cultivated in WLM plus linezolid for $24 \mathrm{~h}$. This effect was amplified after a long exposure (16 weeks) to the WLM, especially when combined with a high glucose concentration and sub-MIC of the antibiotic (Figures 2 and 3), applying stress involving a rapid biofilm formation and consistent with the development of a hyper-adhesive phenotype, as previously observed [49]. Studies have shown 
that linezolid was a potent inhibitor of hla and sea genes' expression in a concentrationdependent manner owing to a positive regulation of agr gene [24]. Our results confirmed that these three genes were clearly affected in the same manner by the environmental condition encountered in DFI, while these genes were significantly over-expressed in the presence of sub-MICs of linezolid alone or in combination with glucose (Table 4). The effect of linezolid on agr expression is of importance. The link between the dysfunction of this major virulence regulatory system in $S$. aureus and chronic infections has been described [50]. As we noted in our study, this gene plays a crucial role in the evolution to persister cells' formation and SCVs under antibiotic pressure [50]. The negative impact of linezolid on hemolytic activity has also been noted [51]. Moreover, sub-MICs of linezolid induced a decrease in spa expression [21,52]. Although this trend was observed in all the studied strains after a short exposure ( $24 \mathrm{~h}$ ) (Supplementary Materials Table S4), the opposite results were observed after a long exposure in the WLM plus linezolid alone or in combination with glucose, suggesting that $S$. aureus clearly modified its virulence in this environment.

Table 4. Overview of effect of glucose and sub-MIC antibiotic concentrations on S. aureus virulence expression from an in vitro wound-like medium (WLM) mimicking the conditions encountered in chronic wounds.

\begin{tabular}{|c|c|c|c|c|}
\hline & \multicolumn{4}{|c|}{ Effect on Expression of Virulence Factor ${ }^{1}$} \\
\hline & PVL & EDIN & Alpha-Hemolysin & Protein A \\
\hline \multicolumn{5}{|c|}{ Short exposure in WLM added to } \\
\hline Glucose & $\uparrow \uparrow$ & $\uparrow \uparrow$ & - & $\downarrow$ \\
\hline Vancomycin & - & - & - & - \\
\hline Linezolid & $\uparrow \uparrow$ & $\downarrow$ & $\downarrow$ & $\downarrow$ \\
\hline \multicolumn{5}{|c|}{ Long exposure in WLM added to } \\
\hline Glucose & $\downarrow$ & $\downarrow$ & $\downarrow$ & $\uparrow$ \\
\hline Vancomycin & - & $\downarrow \downarrow$ & $\uparrow$ & $\downarrow$ \\
\hline Linezolid & $\downarrow \downarrow$ & $\downarrow \downarrow$ & $\downarrow$ & $\uparrow$ \\
\hline
\end{tabular}

The influence of vancomycin on bacterial virulence was totally different compared with linezolid exposure. This antibiotic had limited effects on S. aureus virulence after a short exposure, as previously published [24]. In C. elegans, no significant modification of bacterial virulence could be noted (Table 3). As seen above, the impact of antibiotics on agr expression is crucial. Vancomycin increased the expression of this regulator influencing the virulence by acting on the expression of several virulence genes and by limiting the colonizing behaviour of the bacteria. This trend was confirmed by a huge impact of vancomycin to $\beta$-hemolytic activity and the low presence of SCVs even after prolonged exposure in the WLM. Vancomycin-induced upregulation of enterotoxin expression has previously been described during the first $8 \mathrm{~h}$ in an in vitro hollow-fiber infection model, followed by a downregulation [53]. Our study confirmed this result. Moreover, previous studies indicated that the effects of vancomycin on spa expression were variable [24]. We confirmed that this antibiotic had no relevant impact when used in sub-MIC after a short exposure. In contrast, a significant decrease of spa expression was found after a long exposure in the WLM (Table 4).

Finally, the addition of glucose and antistaphylococcal antibiotics demonstrated the main influence of glucose on the bacterial virulence. If the association of glucose plus linezolid impacted more negatively the expressions of $S$. aureus virulence genes, the combination of glucose and vancomycin was clearly influenced by glucose, while a reversed effect of vancomycin alone on genes' expression level was observed. This is probably due to preferentially interaction between glucose and regulatory genes of $S$. aureus virulence. Further investigations must be developed to confirm this trend.

The PVL is the most studied bi-component leukotoxin produced by S. aureus [6]. This toxin confers cytotoxicity on neutrophils and monocytes-macrophages, leading to a 
high virulence [54]. The PVL-positive strains are responsible for SSTIs, severe necrotizing pneumonia, and aggressive bone and joint infections [55-57]. In DFI, the role of PVL in the pathogenicity of S. aureus is not clearly established. Firstly, the PVL-producing strains are rarely isolated from this pathology [6]. Its prevalence varies between countries: France $(\sim 3 \%)$, Algeria, and The Netherlands ( 14\%) [6]. Classically, the different PVL clones are equally distributed among the various DFI grades. The majority of Grade 1 ulcers where PVL-positive strains were isolated had a rapid clinical amelioration [31]. Moreover, no strains harboring pvl gene have been isolated from diabetic foot osteomyelitis (DFOM) [58]. In this study, we explored the impact of environmental conditions on the expression of this gene. We observed that NSA1077 presented a significant decrease of the pvl expression after a long exposure in the WLM plus glucose, linezolid, and glucose + linezolid and glucose + vancomycin (Table 4). The antitoxin effect of sub-MICs of linezolid has been previously published [24]. This antibiotic induced concentration-dependent decreases in pol expression and PVL production. Surprisingly, the pol expression was strongly increased after a short exposure to linezolid, in contrast to previous publications. One hypothesis could be the role of the medium used in this study. Interestingly, we observed the same effect when the bacteria were exposed to glucose + linezolid, although to a lesser degree (Figure 2). Sub-MICs of vancomycin have no relevant impact on pol expression [24]. Despite confirming this trend in our study after $24 \mathrm{~h}$ exposure to this antibiotic, we observed a significant effect when vancomycin was combined with $10 \%$ glucose, with an increase of pol expression after $24 \mathrm{~h}$ and a strong decrease of expression after 16 weeks. We suggest that the observed effect was mainly due to glucose.

The same trend was also observed for EDIN toxins. These proteins are members of a group of major bacterial virulence factors targeting host Rho GTPases [59]. Recent findings suggest that EDIN toxins might favor bacterial dissemination in tissues by a hematogenous route, through the induction of large transcellular tunnels in endothelial cells named macroapertures [60-62]. In addition, Munro et al. showed that EDIN toxins promote the formation of infection foci in a mouse model of bacteremia [63]. Previous studies on the prevalence of edin genes in DFI showed that these genes are rarely isolated in this pathology [64]. EDIN might collaborate with the arsenal of $S$. aureus virulence factors to confer a higher potential for systemic infection [60]. However, bacteremia is a rare complication in DFI [5], possibly because of the impact of environment, as we observed in this work. Altogether, our study corroborates that $S$. aureus can adapt to different environments and infection phases; this adaptation is modulated by tight transcriptional and (post)translational regulation of its virulence factors.

\section{Conclusions}

DFI is a complex environment where multiple bacterial species coexist. The interface between host and bacteria directly affects the healing of the wound. In these chronic ulcers, the virulence of bacteria is influenced by their intrinsic virulence profile and virulent factor equipment, but also by the environmental conditions and the phenotypic switch that these environmental stresses induce. Here, we showed that toxinogenic and non-toxinogenic S. aureus decreased their virulence in a WLM mimicking the conditions encountered in chronic wounds or/and required to establish chronic wounds. Our observations deserve to be placed in perspective with the clinical situation and epidemiological data where toxinogenic strains are absent from DFI or DFOM, suggesting that these strains have no clear virulence in this context. Subsequent studies are required to understand how bacteria could adapt their virulence in chronic conditions and to correlate these in vitro data using clinical strains. Such studies are pivotal for better ways to manage of DFU and could help in defining new therapeutics. 


\section{Materials and Methods}

\subsection{Bacterial Strains and Growth Conditions}

All bacterial strains used in this study are listed in Table 1.

NSA739, 1077, and 7475 are infecting strains isolated from deep DFI. The strain 1077 was PVL+ and EDIN-B+; the strain 7475 was EDIN-B+. NSA1385 was a colonizing strain isolated from an uninfected ulcer, and NSA739 was isolated from DFI.

The avirulent Escherichia coli OP50 was used as a food source and a control for the nematode assays.

We used the in vitro WLM adapted from De Leon et al. that mimics the conditions encountered in the wound [30]. Briefly, the WLM contained 45\% Bolton broth, 50\% bovine plasma, and 5\% laked horse red blood cells. A $1 \mathrm{~mL}$ volume of VLM was placed in a $14.5 \mathrm{~cm}$ by $1.8 \mathrm{~cm}$ glass tube, inoculated with approximatively $10^{4}$ to $10^{5} \mathrm{CFU}$ of $S$. aureus. The strains were grown in different conditions described in Figure 1 . Thus, bacteria were grown at $37^{\circ} \mathrm{C}$ with shaking at $220 \mathrm{rpm}$ in WLM supplemented with $10 \%$ glucose and/or subinhibitory concentration of antibiotics (sub-MICs, $0.5 \times$ MIC linezolid and vancomycin). Every day, the optical density was adjusted to OD 0.1. Cultures were maintained for 16 weeks (Figure 1).

The vancomycin and linezolid MICs were determined for each strain by the microdilution method in Mueller-Hinton (MH) as recommended by the European Committee for Antimicrobial Susceptibility Testing (EUCAST) [65]. The impact of sub-MIC exposure for 16 weeks on MICs of the different $S$. aureus strains was evaluated each week. No significant difference could be noted (less than threefold dilution). However, the concentration of antibiotics used in the prolonged cultures was always adapted to these MICs.

Then, $100 \mu \mathrm{L}$ samples of culture were plated on Columbia agar supplemented with $5 \%$ fresh sheep blood (bioMérieux, Marcy l'Etoile, France) at $37^{\circ} \mathrm{C}$ each week to assess the loss of beta-hemolysin in each condition.

\subsection{Nematode Killing Assay}

The C. elegans infection assay was performed as previously described using the Fer-15 mutant line, which has a temperature sensitive fertility defect [66]. Fer-15 was provided by the Caenorhabditis Genetics Center, which is funded by the NIH National Center for Research Resources (NCRR). To synchronize the growth of nematodes, eggs were collected using the hypochlorite method. Overnight cultures of E. coli strains in nematode growth medium (NGM) were harvested, centrifuged, washed once, and suspended in phosphate buffered saline solution (PBS) at $\mathrm{pH} 7.0$ at a concentration of $10^{5} \mathrm{CFU} / \mathrm{mL}$. NGM agar plates were inoculated with $10 \mu \mathrm{L}$ of bacterial suspension in different conditions (without pre-incubation in WLM, after pre-incubation in WLM alone or with 10\% glucose, sub-MICs of vancomycin or linezolid) and incubated at $37^{\circ} \mathrm{C}$ for $8-10 \mathrm{~h}$. Plates were brought back to room temperature and seeded with $\mathrm{L} 4$ stage $C$. elegans $(\approx 30$ per plate). Plates were then incubated at $25^{\circ} \mathrm{C}$ and scored each day for live nematode under a stereomicroscope (Leica MS5). A nematode was considered dead when it no longer responded to touch. C. elegans that died from being trapped by the wall of the plate were excluded from the analysis.

At least three replicates repeated twice were performed for each selected strain. Lethal time 50\% (LT50) corresponded to time (in days) required to kill 50\% of the nematodes. The definition of virulence is limited to a narrow definition of virulence and the direct impact of $S$. aureus on the mortality of the worms. Three replicates were performed for each condition.

\subsection{Feeding Behavior Assays}

For occupancy assays, each bacterial strain was cultured overnight at $25{ }^{\circ} \mathrm{C}$ in $\mathrm{LB}$ media, spotted as a circular lawn on NGM plates, and dried at room temperature for $20 \mathrm{~min}$. Approximately $30 \mathrm{~L} 4$ animals were placed in the center of the bacteria lawn. The number of nematodes inside or outside each lawn was counted after $16 \mathrm{~h}$, as previously described [66]. The results were described in percent occupancy corresponding to the number of C. elegans 
in the bacterial lawn/the total number of nematodes. The experiments were performed in triplicate.

The number of bacteria within the $C$. elegans digestive tract was obtained as previously described [67]. Briefly, nematodes were picked at $72 \mathrm{~h}$, and the surface bacteria were removed by washing the nematodes twice in $\mathrm{M} 9$ medium containing $25 \mu \mathrm{g} / \mathrm{mL}$ gentamicin. The C. elegans were then mechanically disrupted in M9 medium containing $1 \%$ Triton X100 [56]. Serial dilutions of the sample were then plated on LB-agar and the colonies were counted after $24 \mathrm{~h}$. Three replicates were performed for each strain.

\subsection{Biofilm Formation}

To evaluate the biofilm formation, we used the Biofilm ring Test ${ }^{\circledR}\left(\right.$ BioFilm Control ${ }^{\circledR}$, Saint Beauzire, France) following the manufacturer recommendations [68]. Briefly, standardized bacterial cultures were incubated at $37^{\circ} \mathrm{C}$ in 96 -well microtiter plates in the presence of magnetic beads. At set time-points, the plates were placed onto a magnetic block and put in the reader. The images of each well before and after magnetic attraction were analyzed with the BioFilm Control software, which gives a biofilm index (BFI). A high BFI value $(>7)$ corresponds to high mobility of the beads under magnetic action (no biofilm), while a low value $(<2)$ corresponds to full immobilization of the beads due to the sessile cells. Three experiments with two repeats were performed per strain and per incubation time.

All the experiments were performed in BHI medium (=control) as recommended by the manufacturer. To study the impact of different conditions tested on biofilm formation, the strains were pre-cultured for $24 \mathrm{~h}$ or 16 weeks in WLM with or without $10 \%$ glucose and sub-MICs of vancomycin or linezolid. The experiments were done in BHI (the WLM was not adapted to the technology).

\section{5. qRT-PCR Assays}

Virulence genes' expressions of $S$. aureus were quantified under different stress conditions after $24 \mathrm{~h}$ and 16 weeks. The virulence and regulator genes tested were adhesins (fnbpA, spa), toxins ( $h l a, p v l$, sea, edinB), and the global regulator agr (Supplementary Materials Table S5).

Briefly, overnight $S$. aureus cultures obtained in different media were diluted to an $\mathrm{OD}_{600}$ of 0.1 in $\mathrm{MH}$ broth and cultured again until an $\mathrm{OD}_{600}$ of 0.7 was reached. The OD at $600 \mathrm{~nm}$ was then adjusted to 0.75 in Tris buffer $(10 \mathrm{mM})$. A $1.5 \mathrm{~mL}$ aliquot of ODadjusted and washed bacterial suspension was centrifuged at $10,000 \times g$ for $10 \mathrm{~min}$, and the pellets were treated with lysostaphin (Sigma) at a final concentration of $200 \mu \mathrm{g} / \mathrm{mL}$. Total RNA from bacteria pellets was extracted as described by the manufacturer using Qiagen RNeasy Mini kit (Qiagen, Courtaboeuf, France) during exponential stages. RNA was treated with the RNase-Free DNase Set (Qiagen, Courtaboeuf, France). Purity and concentration were determined using the NanoDrop ${ }^{\mathrm{TM}} 2000$ spectrophotometer (Fisher Scientific, Pittsburgh, PA, USA). cDNA was synthesized from $1 \mu \mathrm{g}$ of total RNA for each sample, using the iScript ${ }^{\mathrm{TM}}$ Select cDNA Synthesis Kit (Bio-Rad) with random primers according to the manufacturer's instructions.

Real-time PCR assays were performed in a LightCycler ${ }^{\circledR} 480$ device using the LightCycler FastStart DNA Master PLUS SYBRGreen I kit (Roche, Meylan, France) with 100 ng of cDNA and 10 pmol of target primers (Supplementary Materials Table S5) [18,69-74]. The specificity of the PCR products was tested by melting point analysis. Amplifications were performed in triplicate from three different RNA preparations. The $2^{-\Delta \Delta C T}$ method was used to analyze transcriptional changes in target genes using gyrB as the housekeeping control gene (Supplementary Materials Table S5). Error bars indicate the standard deviation (SD) of three independent experiments. Cycle threshold $(C t)$ values of the different target genes were compared with the $C t$-values of the house-keeping gene ( $g y r B)$. The normalized relative expressions of the studied genes were obtained for each strain following the equation: $2^{-\Delta \Delta C t}\left(\Delta \Delta \mathrm{Ct}=\left(\mathrm{Ct}_{\text {gene }}-\mathrm{Ct}_{\text {gyrB }}\right)_{\text {studied strain in different conditions }}-\right.$ 
$\left.\left(C t_{\text {gene }}-\mathrm{Ct}_{\text {gyrB }}\right)_{\text {studied strain in LB medium }}\right)$ [75]. The results obtained for each gene were log-transformed to obtain a fold change difference between strains and conditions used.

\subsection{Statistical Analysis}

Statistics and graphs were prepared using the software package (GraphPad Prism 8.0, GraphPad Software, San Diego, CA, USA).

The comparison between the behavior of $S$. aureus in the in vitro medium alone versus in different conditions was assessed using one-way analysis of variance (ANOVA) followed by Dunnett's multiple comparisons test.

For the nematode killing assays, differences in survival rates between the different strains were tested by a log-rank (Mantel-cox) test for statistical significance.

Log-transformed data were used for qRT-PCR. The effects of the different additions to the WLM medium on the expression of selected genes and a regulator of $S$. aureus were assessed using one-way analysis of variance (ANOVA), followed by Dunnett's multiple comparisons test.

The kinetics of biofilm formation were compared by two-way ANOVA, followed by Dunnett's multiple comparison test.

A $p<0.05$ was considered to reflect a statistically significant difference.

Supplementary Materials: The following are available online at https:/ / www.mdpi.com/2072-665 1/13/3/230/s1, Table S1: Phenotypical modifications of S. aureus cultivated in an in vitro wound-like medium (WLM) mimicking the conditions encountered in chronic wounds and with the addition of high glucose concentration and antibiotics during $24 \mathrm{~h}$. Table S2: Evaluation of feeding behavior by measuring bacterial content of $C$. elegans and pathogen avoidance of $S$. aureus cultivated in an in vitro wound-like medium (WLM) mimicking the conditions encountered in chronic wounds and with the addition of high glucose concentration and antibiotics during 16 weeks. Table S3: Effects of a preculture in a WLM and glucose $10 \%$ associated or not to sub-MICs of vancomycin $(0.5 \times$ MIC) and linezolid $(0.5 \times \mathrm{MIC})$ on S. aureus biofilm formation after $24 \mathrm{~h}$ of culture. The kinetics of the early phase of biofilm formation were determined on (a) NSA739; (b) NSA1077; (c) NSA7475; and (d) NSA1385 by the BioFilm ring test ${ }^{\circledR}($ BioFilm Control, France). The results represent the mean of BFIs for at least three independent replicates. Table S4: Relative mRNA expression levels of virulence genes of four S. aureus strains cultivated in a WLM added with glucose $10 \%$, vancomycin $(0.5 \times$ MIC), linezolid $(0.5 \times \mathrm{MIC})$, glucose $10 \%+$ vancomycin $(0.5 \times \mathrm{MIC})$, and glucose $10 \%+$ linezolid $(0.5 \times \mathrm{MIC})$ after $24 \mathrm{~h}$ (H24) and 16 weeks (W16). Table S5: Primers used in the study.

Author Contributions: Conceptualization, C.P., A.S., F.L., E.L., C.D.-R. and J.-P.L.; methodology, C.D.-R. and J.-P.L.; validation, F.L. and A.T.; formal analysis, C.P., C.-A.G. and C.N.-E.; investigation, C.P., C.-A.G. and C.N.-E.; writing-original draft preparation, C.P. and J.-P.L.; writing-review and editing, C.-A.G., C.N.-E., F.L., E.L., A.T., A.S. and C.D.-R.; visualization: F.L. and A.T.; supervision, C.D.-R. and J.-P.L.; project investigation: A.S., C.D.-R. and J.-P.L.; funding acquisition: A.S. and J.-P.L. All authors have read and agreed to the published version of the manuscript.

Funding: Cassandra Pouget's PhD is supported by a CIFRE grant (Biofilm Pharma).

Institutional Review Board Statement: Not applicable.

Informed Consent Statement: Not applicable.

Data Availability Statement: Data sharing not applicable.

Acknowledgments: We thank Sarah Kabani for her editing assistance. We thank the Nîmes University hospital for its structural, human, and financial support through the award obtained by our team during the internal call for tenders "Thématiques phares". The authors belong to the FHU InCh (Federation Hospitalo Universitaire Infections Chroniques, Aviesan).

Conflicts of Interest: The authors declare no conflict of interest. The funders had no role in the design of the study; in the collection, analyses, or interpretation of data; in the writing of the manuscript; or in the decision to publish the results. 


\section{References}

1. Armstrong, D.G.; Boulton, A.J.; Bus, S.A. Diabetic foot ulcers and their recurrence. N. Engl. J. Med. 2017, 376, 2367-2375. [CrossRef]

2. Lecube, A.; Pachón, G.; Petriz, J.; Hernández, C.; Simó, R. Phagocytic activity is impaired in type 2 diabetes mellitus and in-creases after metabolic improvement. PLOS ONE 2011, 6, e23366. [CrossRef]

3. Tesfaye, S.; Boulton, A.J.; Dyck, P.J.; Freeman, R.; Horowitz, M.; Kempler, P.; Lauria, G.; Malik, R.A.; Spallone, V.; Vinik, A.; et al. Diabetic neuropathies: Update on definitions, diagnostic criteria, estimation of severity, and treatments. Diabetes Care 2010, 33, 2285-2293. [CrossRef] [PubMed]

4. Chawla, R.; Chawla, A.; Jaggi, S. Microvasular and macrovascular complications in diabetes mellitus: Distinct or continuum? Indian J. Endocrinol. Metab. 2016, 20, 546-551. [CrossRef]

5. Bakker, K.; Apelqvist, J.; Lipsky, B.A.; Van Netten, J.J.; Schaper, N.C.; International Working Group on the Diabetic Foot (IWGDF). The 2015 IWGDF guidance documents on prevention and management of foot problems in diabetes: Development of an evidence-based global consensus. Diabetes Metab. Res. Rev. 2016, 32, 2-6. [CrossRef] [PubMed]

6. Dunyach-Remy, C.; Essebe, C.N.; Sotto, A.; Lavigne, J.-P. Staphylococcus aureus toxins and diabetic foot ulcers: Role in pathogenesis and interest in diagnosis. Toxins 2016, 8, 209. [CrossRef]

7. Pouget, C.; Dunyach-Remy, C.; Pantel, A.; Schuldiner, S.; Sotto, A.; Lavigne, J.-P. Biofilms in diabetic foot ulcers: Significance and clinical relevance. Microorganisms 2020, 8, 1580. [CrossRef]

8. Chakraborty, S.P.; Mahapatra, S.K.; Sahu, S.K.; Chattopadhyay, S.; Pramanik, P.; Roy, S. Nitric oxide mediated Staphylococcus aureus pathogenesis and protective role of nanoconjugated vancomycin. Asian Pac. J. Trop. Biomed. 2011, 1, 102-109. [CrossRef]

9. Josse, J.; Laurent, F.; Diot, A. Staphylococcal adhesion and host cell invasion: Fibronectin-binding and other mechanisms. Front. Microbiol. 2017, 8, 2433. [CrossRef] [PubMed]

10. Falugi, F.; Kim, H.K.; Missiakas, D.M.; Schneewind, O. Role of protein A in the evasion of host adaptive immune responses by Staphylococcus aureus. mBio 2013, 4, e00575-13. [CrossRef]

11. Bisognano, C.; Vaudaux, P.; Rohner, P.; Lew, D.P.; Hooper, D.C. Induction of fibronectin-binding proteins and increased adhesion of quinolone-resistant Staphylococcus aureus by subinhibitory levels of ciprofloxacin. Antimicrob. Agents Chemother. 2000, 44, 1428-1437. [CrossRef] [PubMed]

12. Harraghy, N.; Kormanec, J.; Wolz, C.; Homerova, D.; Goerke, C.; Ohlsen, K.; Qazi, S.; Hill, P.; Herrmann, M. Sae is essential for expression of the staphylococcal adhesins Eap and Emp. Microbiology 2005, 151, 1789-1800. [CrossRef] [PubMed]

13. Saeed, K.; Gould, I.; Esposito, S.; Ahmad-Saeed, N.; Ahmed, S.S.; Alp, E.; Bal, A.M.; Bassetti, M.; Bonnet, E.; Chan, M.; et al. Panton-Valentine leukocidin-positive Staphylococcus aureus: A position statement from the international society of chemotherapy. Int. J. Antimicrob. Agents 2018, 51, 16-25. [CrossRef] [PubMed]

14. Courjon, J.; Munro, P.; Benito, Y.; Visvikis, O.; Bouchiat, C.; Boyer, L.; Doye, A.; Lepidi, H.; Ghigo, E.; Lavigne, J.-P.; et al. EDIN-B promotes the translocation of Staphylococcus aureus to the bloodstream in the course of pneumonia. Toxins 2015, 7, 4131-4142. [CrossRef] [PubMed]

15. Franke, G.C.; Böckenholt, A.; Sugai, M.; Rohde, H.; Aepfelbacher, M. Epidemiology, variable genetic organization and regu-lation of the EDIN-B toxin in Staphylococcus aureus from bacteraemic patients. Microbiology 2010, 156, 860-872. [CrossRef]

16. Grumann, D.; Nübel, U.; Bröker, B.M. Staphylococcus aureus toxins-Their functions and genetics. Infect. Genet. Evol. 2014, 21, 583-592. [CrossRef]

17. Tuchscherr, L.; Löffler, B.; Proctor, R.A. Persistence of Staphylococcus aureus: Multiple metabolic pathways impact the expression of virulence factors in small-colony variants (SCVs). Front. Microbiol. 2020, 11, 1028. [CrossRef]

18. Heravi, F.S.; Zakrzewski, M.; Vickery, K.; Malone, M.; Hu, H. Metatranscriptomic analysis reveals active bacterial communities in diabetic foot infections. Front. Microbiol. 2020, 11, 1688. [CrossRef]

19. Richard, J.-L.; Lavigne, J.-P.; Sotto, A. Diabetes and foot infection: More than double trouble. Diabetes Metab. Res. Rev. 2012, 28, 46-53. [CrossRef]

20. Dumitrescu, O.; Boisset, S.; Badiou, C.; Bes, M.; Benito, Y.; Reverdy, M.E.; Vandenesch, F.; Etienne, J.; Lina, G. Effect of anti-biotics on Staphylococcus aureus producing panton-valentine leukocidin. Antimicrob. Agents Chemother. 2007, 51, 1515-1519. [CrossRef]

21. Otto, M.P.; Martin, E.; Badiou, C.; Lebrun, S.; Bes, M.; Vandenesch, F.; Etienne, J.; Lina, G.; Dumitrescu, O. Effects of subin-hibitory concentrations of antibiotics on virulence factor expression by community-acquired methicillin-resistant Staphylococcus aureus. J. Antimicrob. Chemother. 2013, 68, 1524-1532. [CrossRef] [PubMed]

22. O'Brien, D.J.; Gould, I.M. Does vancomycin have a future in the treatment of skin infections? Curr. Opin. Infect. Dis. 2014, 27, 146-154. [CrossRef]

23. Mauriello, C.T.; Hair, P.S.; Rohn, R.D.; Rister, N.S.; Krishna, N.K.; Cunnion, K.M. Hyperglycemia inhibits complement-mediated immunological control of S. aureus in a rat model of peritonitis. J. Diabetes Res. 2014, 2014, 762051. [CrossRef]

24. Hodille, E.; Rose, W.; Diep, B.A.; Goutelle, S.; Lina, G.; Dumitrescu, O. The role of antibiotics in modulating virulence in Straphylococcus aureus. Clin. Microbiol. Rev. 2017, 30, 887-917. [CrossRef]

25. Yang, D.; Wijenayaka, A.R.; Solomon, L.B.; Pederson, S.M.; Findlay, D.M.; Kidd, S.P.; Atkins, G.J. Novel insights into Staphy-lococcus aureus deep bone infections: The involvement of osteocytes. mBio 2018, 8, e00415-18.

26. Bui, L.M.; Turnidge, J.D.; Kidd, S.P. The induction of Staphylococcus aureus biofilm formation or small colony variants is a strain-specific response to host-generated chemical stresses. Microbes Infect. 2015, 17, 77-82. [CrossRef] [PubMed] 
27. Bui, L.M.G.; Hoffmann, P.; Turnidge, J.D.; Zilm, P.S.; Kidd, S.P. Prolonged growth of a clinical Staphylococcus aureus strain selects for a stable small-colony-variant cell type. Infect. Immun. 2014, 83, 470-481. [CrossRef]

28. Lee, J.; Zilm, P.S.; Kidd, S.P. Novel Research Models for Staphylococcus aureus small colony variants (SCV) development: Copathogenesis and Growth Rate. Front. Microbiol. 2020, 11, 321. [CrossRef]

29. Sun, Y.; Dowd, S.E.; Smith, E.; Rhoads, D.D.; Wolcott, R.D. In vitro multispecies Lubbock chronic wound biofilm model. Wound Repair Regen. 2008, 16, 805-813. [CrossRef]

30. DeLeon, S.; Clinton, A.; Fowler, H.; Everett, J.; Horswill, A.R.; Rumbaugh, K.P. Synergistic interactions of Pseudomonas aeruginosa and Staphylococcus aureus in an in vitro wound model. Infect. Immun. 2014, 82, 4718-4728. [CrossRef] [PubMed]

31. Sotto, A.; Lina, G.; Richard, J.-L.; Combescure, C.; Bourg, G.; Vidal, L.; Jourdan, N.; Etienne, J.; Lavigne, J.-P. Virulence Potential of Staphylococcus aureus strains isolated from diabetic foot ulcers: A new paradigm. Diabetes Care 2008, 31, 2318-2324. [CrossRef]

32. Sotto, A.; Richard, J.-L.; Messad, N.; Molinari, N.; Jourdan, N.; Schuldiner, S.; Sultan, A.; Carrière, C.; Canivet, B.; Landraud, L.; et al. Distinguishing colonization from infection with Staphylococcus aureus in diabetic foot ulcers with miniaturized oligonucleotide arrays: A French multicenter study. Diabetes Care 2012, 35, 617-623. [CrossRef] [PubMed]

33. Liu, C.; Ponsero, A.J.; Armstrong, D.G.; Lipsky, B.A.; Hurwitz, B.L. The dynamic wound microbiome. BMC Med. 2020, 18, 1-12. [CrossRef] [PubMed]

34. Spichler, A.; Hurwitz, B.L.; Armstrong, D.G.; Lipsky, B.A. Microbiology of diabetic foot infections: From Louis Pasteur to 'crime scene investigation'. BMC Med. 2015, 13, 2. [CrossRef] [PubMed]

35. Dowd, S.E.; Wolcott, R.D.; Sun, Y.; McKeehan, T.; Smith, E.; Rhoads, D. Polymicrobial nature of chronic diabetic foot ulcer biofilm infections determined using bacterial tag encoded flx amplicon pyrosequencing (bTEFAP). PLoS ONE 2008, 3, e3326. [CrossRef] [PubMed]

36. Pereira, S.G.; Moura, J.; Carvalho, E.; Empadinhas, N. Microbiota of chronic diabetic wounds: Ecology, impact, and potential for innovative treatment strategies. Front. Microbiol. 2017, 8, 1791. [CrossRef]

37. Hibbing, M.E.; Fuqua, C.; Parsek, M.R.; Peterson, S.B. Bacterial competition: Surviving and thriving in the microbial jungle. Nat. Rev. Genet. 2009, 8, 15-25. [CrossRef] [PubMed]

38. Kalan, L.R.; Meisel, J.S.; Loesche, M.A.; Horwinski, J.; Soaita, I.; Chen, X.; Uberoi, A.; Gardner, S.E.; Grice, E.A. Strain-and Species-Level variation in the microbiome of diabetic wounds is associated with clinical outcomes and therapeutic efficacy. Cell Host Microbe 2019, 25, 641-655.e5. [CrossRef]

39. James, G.A.; Swogger, E.; Wolcott, R.; Pulcini, E.D.; Secor, P.; Sestrich, J.; Costerton, J.W.; Stewart, P.S. Biofilms in chronic wounds. Wound Repair Regen. 2008, 16, 37-44. [CrossRef]

40. Malone, M.; Bjarnsholt, T.; McBain, A.; James, G.; Stoodley, P.; Leaper, D.; Tachi, M.; Schultz, G.; Swanson, T.; Wolcott, R. The prevalence of biofilms in chronic wounds: A systematic review and meta-analysis of published data. J. Wound Care 2017, 26, 20-25. [CrossRef]

41. Clinton, A.; Carter, T. Chronic wound biofilms: Pathogenesis and potential therapies. Lab. Med. 2015, 46, 277-284. [CrossRef]

42. Regassa, L.B.; Couch, J.L.; Betley, M.J. Steady-state staphylococcal enterotoxin type C mRNA is affected by a product of the accessory gene regulator (AGR) and by glucose. Infect. Immun. 1991, 59, 955-962. [CrossRef] [PubMed]

43. Gotz, F. Staphylococcus and biofilms. Mol. Microbiol. 2002, 43, 1367-1378. [CrossRef] [PubMed]

44. Waldrop, R.; McLaren, A.; Calara, F.; McLemore, R. Biofilm growth has a threshold response to glucose in vitro. Clin. Orthop. Relat. Res. 2014, 472, 3305-3310. [CrossRef] [PubMed]

45. Bischoff, M.; Wonnenberg, B.; Nippe, N.; Nyffenegger-Jann, N.J.; Voss, M.; Beisswenger, C.; Sunderkötter, C.; Molle, V.; Dinh, Q.T.; Lammert, F.; et al. CcpA affects infectivity of Staphylococcus aureus in a hyperglycemic environment. Front. Cell. Infect. Microbiol. 2017, 7, 172. [CrossRef] [PubMed]

46. You, Y.; Xue, T.; Cao, L.; Zhao, L.; Sun, H.; Sun, B. Staphylococcus aureus glucose-induced biofilm accessory proteins, GbaAB, influence biofilm formation in a PIA-dependent manner. Int. J. Med. Microbiol. 2014, 304, 603-612. [CrossRef] [PubMed]

47. Cohen, T.S.; Takahashi, V.; Bonnell, J.; Tovchigrechko, A.; Chaerkady, R.; Yu, W.; Jones-Nelson, O.; Lee, Y.; Raja, R.; Hess, S.; et al. Staphylococcus aureus drives expansion of low-density neutrophils in diabetic mice. J. Clin. Investig. 2019, 129, 2133-2144 [CrossRef] [PubMed]

48. Shaji, B.V.; Shaji, S.; Haritha, V.H.; Pramod, S.; Anie, Y. Calcium depletion at high glucose concentration promotes vesicle-mediated NET release in response to Staphylococcus aureus. Mol. Immunol. 2020, 124, 211-217. [CrossRef]

49. Rasigade, J.-P.; Moulay, A.; Lhoste, Y.; Tristan, A.; Bes, M.; Vandenesch, F.; Etienne, J.; Lina, G.; Laurent, F.; Dumitrescu, O. Impact of sub-inhibitory antibiotics on fibronectin-mediated host cell adhesion and invasion by Staphylococcus aureus. BMC Microbiol. 2011, 11, 263. [CrossRef]

50. Häffner, N.; Bär, J.; Haunreiter, V.D.; Shambat, S.M.; Seidl, K.; Crosby, H.A.; Horswill, A.R.; Zinkernagel, A.S. Intracellular environment and AGR System affect colony size heterogeneity of Staphylococcus aureus. Front. Microbiol. 2020, 11, 1415. [CrossRef]

51. Gemmell, C.G.; Ford, C.W. Virulence factor expression by Gram-positive cocci exposed to sub-inhibitory concentrations of linezolid. J. Antimicrob. Chemother. 2002, 50, 665-672. [CrossRef]

52. Bernardo, K.; Pakulat, N.; Fleer, S.; Schnaith, A.; Utermöhlen, O.; Krut, O.; Müller, S.; Krönke, M. Subinhibitory concentrations of linezolid reduce Staphylococcus aureus virulence factor expression. Antimicrob. Agents Chemother. 2004, 48, 546-555. [CrossRef] [PubMed] 
53. Pichereau, S.; Pantrangi, M.; Couet, W.; Badiou, C.; Lina, G.; Shukla, S.K.; Rose, W.E. Simulated antibiotic exposures in an in vitro hollow-fiber infection model influence toxin gene expression and production in community-associated methicillin-resistant Staphylococcus aureus Strain MW2. Antimicrob. Agents Chemother. 2011, 56, 140-147. [CrossRef] [PubMed]

54. Boyle-Vavra, S.; Daum, R.S. Community-acquired methicillin-resistant Staphylococcus aureus: The role of Panton-Valentine leukocidin. Lab. Investig. 2006, 87, 3-9. [CrossRef]

55. Vandenesch, F.; Lina, G.; Henry, T. Staphylococcus aureus hemolysins, bi-component leukocidins, and cytolytic peptides: A redundant arsenal of membrane-damaging virulence factors? Front. Cell. Infect. Microbiol. 2012, 2, 12. [CrossRef] [PubMed]

56. Shallcross, L.J.; Fragaszy, E.; Johnson, A.M.; Hayward, A.C. The role of the Panton-Valentine leucocidin toxin in staphylococcal disease: A systematic review and meta-analysis. Lancet Infect. Dis. 2013, 13, 43-54. [CrossRef]

57. Gillet, Y.; Issartel, B.; Vanhems, P.; Fournet, J.-C.; Lina, G.; Bes, M.; Vandenesch, F.; Piémont, Y.; Brousse, N.; Floret, D.; et al. Association between Staphylococcus aureus strains carrying gene for Panton-Valentine leukocidin and highly lethal necrotising pneumonia in young immunocompetent patients. Lancet 2002, 359, 753-759. [CrossRef]

58. Senneville, E.; Brière, M.; Neut, C.; Messad, N.; Lina, G.; Richard, J.-L.; Sotto, A.; Lavigne, J.-P. First report of the predominance of clonal complex 398 Staphylococcus aureus strains in osteomyelitis complicating diabetic foot ulcers: A national French study. Clin. Microbiol. Infect. 2014, 20, O274-O277. [CrossRef]

59. Boquet, P.; Lemichez, E. Bacterial virulence factors targeting Rho GTPases: Parasitism or symbiosis? Trends Cell Biol. 2003, 13, 238-246. [CrossRef]

60. Boyer, L.; Doye, A.; Rolando, M.; Flatau, G.; Munro, P.; Gounon, P.; Clément, R.; Pulcini, C.; Popoff, M.R.; Mettouchi, A.; et al. Induction of transient macroapertures in endothelial cells through RhoA inhibition by Staphylococcus aureus factors. J. Cell Biol. 2006, 173, 809-819. [CrossRef]

61. Lemichez, E.; Lecuit, M.; Nassif, X.; Bourdoulous, S. Breaking the wall: Targeting of the endothelium by pathogenic bacteria. Nat. Rev. Genet. 2009, 8, 93-104. [CrossRef] [PubMed]

62. Rolando, M.; Munro, P.; Stefani, C.; Auberger, P.; Flatau, G.; Lemichez, E. Injection of Staphylococcus aureus EDIN by the Bacillus anthracis protective antigen machinery induces vascular permeability. Infect. Immun. 2009, 77, 3596-3601. [CrossRef] [PubMed]

63. Munro, P.; Benchetrit, M.; Nahori, M.-A.; Stefani, C.; Clément, R.; Michiels, J.-F.; Landraud, L.; Dussurget, O.; Lemichez, E. The Staphylococcus aureus epidermal cell differentiation inhibitor toxin promotes formation of infection foci in a mouse model of bacteremia. Infect. Immun. 2010, 78, 3404-3411. [CrossRef] [PubMed]

64. Messad, N.; Landraud, L.; Canivet, B.; Lina, G.; Richard, J.-L.; Sotto, A.; Lavigne, J.-P.; Lemichez, E. Distribution of edin in Staphylococcus aureus isolated from diabetic foot ulcers. Clin. Microbiol. Infect. 2013, 19, 875-880. [CrossRef] [PubMed]

65. The European Committee on Antimicrobial Susceptibility Testing. Breakpoint Tables for Interpretation of MICs and Zone Diameters. Version 10.0. 2020. Available online: http://www.eucast.org/fileadmin/src/media/PDFs/EUCAST_files/Breakpoint_ tables/v_10.0_Breakpoint_Tables.pdf (accessed on 8 February 2021).

66. Essebe, C.N.; Visvikis, O.; Fines-Guyon, M.; Vergne, A.; Cattoir, V.; Lecoustumier, A.; Lemichez, E.; Sotto, A.; Lavigne, J.-P.; Dunyach-Remy, C. Decrease of Staphylococcus aureus virulence by Helcococcus kunzii in a Caenorhabditis elegans model. Front. Cell. Infect. Microbiol. 2017, 7, 77. [CrossRef]

67. Garsin, D.A.; Sifri, C.D.; Mylonakis, E.; Qin, X.; Singh, K.V.; Murray, B.E.; Calderwood, S.B.; Ausubel, F.M. A simple model host for identifying Gram-positive virulence factors. Proc. Natl. Acad. Sci. USA 2001, 98, 10892-10897. [CrossRef]

68. Chavant, P.; Gaillard-Martinie, B.; Talon, R.; Hebraud, M.; Bernardi, T. A new device for rapid evaluation of biofilm formation potential by bacteria. J. Microbiol. Methods 2007, 68, 605-612. [CrossRef]

69. Qiu, J.; Feng, H.; Xiang, H.; Wang, D.; Xia, L.; Jiang, Y.; Song, K.; Lu, J.; Yu, L.; Deng, X. Influence of subinhibitory concen-trations of licochalcone A on the secretion of enterotoxins A and B by Staphylococcus aureus. FEMS Microbiol. Lett. 2010, 307, 135-141. [CrossRef]

70. Dumitrescu, O.; Choudhury, P.; Boisset, S.; Badiou, C.; Bes, M.; Benito, Y.; Wolz, C.; Vandenesch, F.; Etienne, J.; Cheung, A.L.; et al. Beta-lactams interfering with PBP1 induce Panton-Valentine leukocidin expression by triggering sarA and rot global regulators of Staphylococcus aureus. Antimicrob. Agents Chemother. 2011, 55, 3261-3271. [CrossRef]

71. Munro, P.; Clément, R.; Lavigne, J.P.; Pulcini, C.; Lemichez, E.; Landraud, L. High prevalence of edin-C encodign RhoA-targeting toxin in clinical isolates of Staphylococcus aureus. Eur. J. Clin. Microbiol. Infect. Dis. 2011, 30, 965-972. [CrossRef]

72. Atshan, S.S.; Shamsudin, M.N.; Karunanidhi, A.; Van Belkum, A.; Lung, L.T.T.; Sekawi, Z.; Nathan, J.J.; Ling, K.H.; Seng, J.S.C.; Ali, A.M.; et al. Quantitative PCR analysis of genes expressed during biofilm development of methicillin resistant Staphylococcus aureus (MRSA). Infect. Genet. Evol. 2013, 18, 106-112. [CrossRef] [PubMed]

73. Labandeira-Rey, M.; Couzon, F.; Boisset, S.; Brown, E.L.; Bes, M.; Benito, Y.; Barbu, E.M.; Vazquez, V.; Höök, M.; Etienne, J.; et al. Staphylococcus aureus Panton-valentine leukocidin causes necrotizing pneumonia. Science 2007, 315, 1130-1133. [CrossRef] [PubMed]

74. Garzoni, C.; Francois, P.; Huyghe, A.; Couzinet, S.; Tapparel, C.; Charbonnier, Y.; Renzoni, A.; Lucchini, S.; Lew, D.P.; Vaudaux, P.; et al. A global view of Staphylococcus aureus whole genome expression upon internalization in human epithelial cells. BMC Genom. 2007, 8, 171. [CrossRef] [PubMed]

75. Livak, K.J.; Schmittgen, T.D. Analysis of relative gene expression data using real-time quantitative PCR and the 2(-Delta Delta C(T)) method. Methods 2001, 25, 402-408. [CrossRef] 